\title{
ELABORAÇÃO E ANÁLISE SENSORIAL DE MASSA DE PIZZA COM FARINHA DE AMÊNDOAS DA CASTANHA DE CAJU
}

\author{
B. A. MORAIS ${ }^{1}$, L. S. LEMOS $^{1}$, M. F. IUNES ${ }^{1}$, S. MIGUEL $^{2}$, M. C. P. RODRIGUES ${ }^{3}$ \\ ${ }^{1}$ Universidade Federal do Ceará, Departamento de Tecnologia de Alimentos, ${ }^{2}$ Escola de Engenharia Purpan \\ (França) e Universidade Federal do Ceará, Departamento de Engenharia de Alimentos, ${ }^{3}$ Universidade \\ Federal do Ceará, Departamento de Tecnologia de Alimentos. \\ E-mail para contato: brena-am@ hotmail.com
}

\begin{abstract}
RESUMO - A amêndoa da castanha de caju é um fruto seco oleaginoso de grande importância social e econômica no Brasil, principalmente na região Nordeste do país. Além de apresentar sabor agradável, produtos com farinha de amêndoas da castanha de caju trazem benefícios por serem ricos em minerais básicos, como ferro, fósforo, selênio, magnésio e zinco. É também uma fonte de antioxidantes e de proteínas. Este trabalho teve como objetivo o desenvolvimento de massa de pizza a partir da substituição da farinha de trigo por farinha de amêndoas da castanha de caju. Avaliou-se a preferência e a aceitação de 60 julgadores não treinados no que concerne às características sensoriais, utilizando testes de comparação pareada e de escala hedônica. A pizza padrão obteve os maiores valores de aceitação referentes aos critérios avaliados. Contudo, as pizzas de farinha de amêndoa obtiveram elevados percentuais de aceitação perante aos atributos estudados, tendo o critério sabor iguais valores de aceitação para as duas pizzas, e a textura como o critério que apresentou um maior percentual de diferença, ainda dentro da faixa de aceitação. A intenção de compra revelou que a pizza de farinha de amêndoas da castanha de caju seria bem aceita no mercado, pois a maior parte dos julgadores afirmou que certamente compraria esse produto.
\end{abstract}

\section{INTRODUÇÃ̃O}

A pizza é um alimento que consiste em um disco de massa fermentada, coberta com molho de tomate e ingredientes variados, como carnes, queijos, orégano, entre outros, assados em forno. Sabe-se também da existência de pizzas doces, que seguem a mesma formulação de massa, porém com ingredientes diferenciados, como chocolate, banana e goiabada. Segundo Marcia Fani (2009), a pizza é difundida em todo o planeta, talvez sendo o prato mais democrático que existe, agradando a maioria das pessoas.

Nos dias atuais, a população preocupa-se cada vez mais com o consumo de alimentos saudáveis, porém, os hábitos alimentares já não são mais os mesmos. As pessoas adquirem, cada vez mais, produtos congelados prontos ou semiprontos, além da grande procura pela rede de fastfoods. Assim, para que a pizza não se torne um alimento com baixa qualidade nutricional e deixe de ser adquirida, vem sendo buscado a partir de pesquisas a elaboração de formulações de massas de pizzas mais saudáveis. Pois, Segundo GALLAGHER apud FARIAS (2009), a qualidade 
total de uma pizza depende principalmente da massa, cujas propriedades são afetadas pelo tipo de farinha e a forma de preparação.

A farinha de trigo é comumente utilizada na produção de massas de pizzas, pães, bolos, tortas, entre outros, devido às propriedades de suas proteínas, que formam uma massa borrachuda pegajosa quando hidratada e misturada, conhecida como glúten. Porém, a presença do glúten na farinha de trigo pode desenvolver em pessoas com predisposição genética a doença celíaca, que é uma intolerância definitiva ao glúten. Já, apesar de possuírem vitaminas do complexo B, zinco e potássio faz-se necessário a busca por farinhas que possam ter suas propriedades semelhantes a da farinha de trigo e, consequentemente, substitui - lá.

Uma farinha que pode ser empregada é a farinha de amêndoas da castanha de caju. Segundo Flormel, 2012, a amêndoa da castanha de caju é um dos frutos secos mais valorizados, principalmente, por ser produzido em países de clima tropical, sendo um fruto seco oleaginoso, de sabor doce e agradável, rica em ácidos graxos não saturados como o oléico e linoléico, além de vitaminas como B1 e B2, potássio, fósforo, zinco, magnésio, ferro e ácido pantotênico.

Assim sendo, a farinha de amêndoas da castanha de caju, apesar de modificar um pouco a cor do produto, pode agregar um melhor valor nutricional à pizza, além da isenção do glúten. Segundo Vilela (2013), essa amêndoa é bastante apreciada no Brasil e no exterior, e sua farinha pode ser utilizada na fabricação de massas, pães, bolos, tortas e biscoitos.

Por conseguinte, o presente trabalho teve como objetivo geral a elaboração e análise sensorial de massa de pizza com farinha de amêndoas da castanha de caju, tendo como referência a massa de pizza tradicional. Foram utilizados testes sensoriais, como Escala Hedônica e Pareado Preferência, com o intuito de analisar a aceitação e preferência dos consumidores, respectivamente, além do que também foi aplicado perguntas sobre a intenção de compra, caso esse produto fosse disponibilizado no mercado.

\section{MATERIAIS E MÉTODOS}

Foram elaboradas duas massas de pizza, uma padrão e outra substituída totalmente pela farinha de amêndoas da castanha de caju.

As massas tiveram como ingredientes a farinha de trigo da marca Dona Benta, farinha amêndoas da castanha de caju da marca Vila Natural, ovos, leite desnatado (UHT) da marca Maranguape, queijo ralado da marca Regina, óleo de soja refinado da marca ABC, sal da marca Qualitá e fermento em pó da marca Royal.

A primeira massa de pizza foi preparada misturando no liquidificador, de marca Mallory, 2 xícaras de leite, 1 ovo,1/2 de colher de chá de sal, 2 e 1/2 xícaras (300g) de farinha de trigo, 1/4 de xícara de óleo de soja refinado, 1 colher de sopa de fermento em pó e 1 colher de sopa de queijo ralado. Já a segunda massa de pizza foi elaborada misturando no liquidificador, de marca Mallory, 
$200 \mathrm{~g}$ de farinha de castanha de caju, 1 ovo, 3/4 de xícara de leite desnatado (UHT), 1 colher de sopa de queijo ralado, 1 colher de sopa de óleo de soja refinado, 1/2 colher de chá de sal e 1 colher de chá de fermento em pó. As massas foram despejadas em assadeira para pizza, levando ao forno préaquecido por cerca de 10 minutos com temperatura de $250^{\circ} \mathrm{C}$. Depois foram retiradas do forno e espalhado o molho de tomate nas mesmas. Em seguida, foram adicionados o queijo mussarela e orégano, levando novamente ao forno, também a $250^{\circ} \mathrm{C}$, até derreter a mussarela (aproximadamente 6 minutos). Em todas as pizzas, já com as massas pré-assadas, foram utilizados 1/2 colher de chá de molho de tomate $(2 \mathrm{ml}), 1 / 2$ colher de chá de orégano $(2 \mathrm{~g})$ e o queijo mussarela no formato da pizza, ou seja, no formato de discos com tamanho padronizado.

\subsection{ANÁLISE SENSORIAL}

Para avaliar a aceitação das massas de pizzas, foram divididas em porções de tamanho semelhantes para avaliação pelos provadores.

A avaliação sensorial foi realizada no Laboratório de Análise Sensorial do Departamento de Engenharia de Alimentos da Universidade Federal do Ceará, aplicando-se o teste de aceitabilidade com ficha de Escala Hedônica de 9 pontos e o teste de Pareado Preferência para determinação da preferência entre a massa de pizza padrão e a massa de pizza de amêndoas da castanha de caju. Nas fichas também foram solicitados aos provadores que respondessem questionários a respeito da frequência de consumo de produtos à base de castanha e a respeito da intenção de compra dos produtos testados. Participaram do teste, como voluntários, 60 provadores não treinados. As amostras foram codificadas com três dígitos e apresentadas em bandejas, junto com um copo plástico contendo água.

Para o teste de Escala Hedônica as amostram foram servidas de forma monadica e sequencial, já para o teste Pareado Preferência as amostras foram servidas simultaneamente, sendo solicitado aos provadores que avaliassem as amostras da esquerda para a direita. Em ambos os testes, foi solicitado que, entre uma amostra e outra, os provadores lavassem o palato com água.

\section{RESULTADOS E DISCUSSÃO}

A massa de pizza com farinha de amêndoas da castanha de caju apresentou coloração mais escura do que a padrão (apenas com farinha de trigo). Durante o preparo, observou-se que a mesma absorveu menos o líquido (leite desnatado Maranguape), já que ela apresenta certa oleosidade. Quanto ao crescimento, devido à adição de fermento em pó, não houve diferença perceptível entre as duas amostras.

Dos 60 provadores que realizaram a análise sensorial, $70 \%$ consumiam pizza $01 \mathrm{vez} / \mathrm{mês,}$ $28,33 \%$ consumiam $2-3$ vezes/semana e $1,67 \%$ consumiam pizza 01 vez/semana. Em relação ao quanto gostavam de farinha de amêndoas da castanha de caju e de produtos derivados dessa farinha, foi alcançado o mesmo percentual de provadores $(36,67 \%)$ para gosto muitíssimo e gosto muito e para gosto moderadamente o percentual atingido foi de $26,67 \%$. Já no que concerne à pergunta 
realizada no questionário sobre a frequência do consumo de pizza com farinha de amêndoas da castanha de caju, apenas um provador relatou o consumo, sendo de 01vez/mês, os outros 98,33\% dos provadores relataram nunca terem consumido.

Teste Pareado Preferência:

Tabela 1. Resultado do teste Pareado Preferência

\begin{tabular}{|c|c|}
\hline AMOSTRA & RESPOSTA \\
\hline A & 24 \\
\hline B & 36 \\
\hline
\end{tabular}

O resultado pode ser encontrado na tabela 01 , onde o número de respostas para a amostra que obteve a maior aceitação dos provadores consultados foi 36 (Amostra B). Todavia, segundo a Tabela Bicaudal para o teste pareado com um número de 60 provadores ao nível de $5 \%$ de significância, haveria diferença significativa se o número de respostas corretas fossem $\geq 39$. Portanto, não houve diferença significativa entre as amostras.

Histogramas de Frequência para cada atributo avaliado

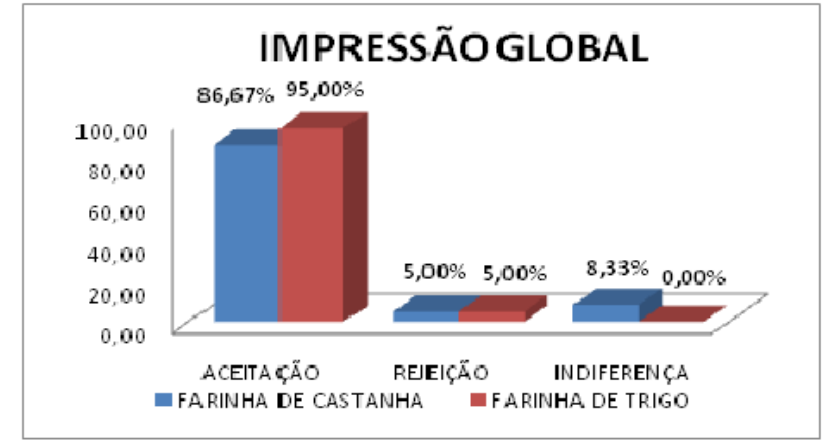

FIGURA 1. Histograma de frequência para impres são global

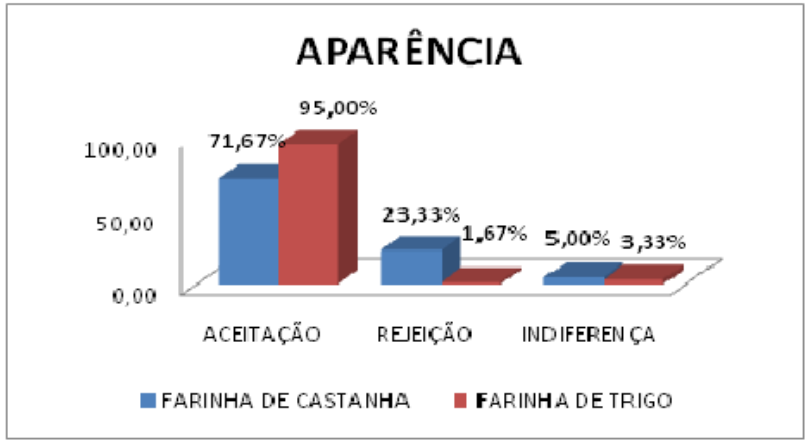

FIGURA 2. Histograma de frequência para aparência

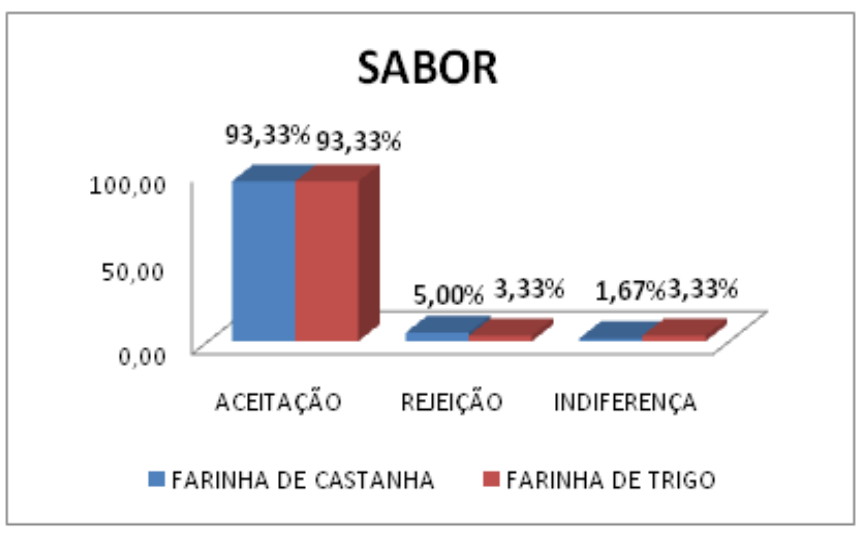

FIGURA 3. Histograma de frequência para sabor

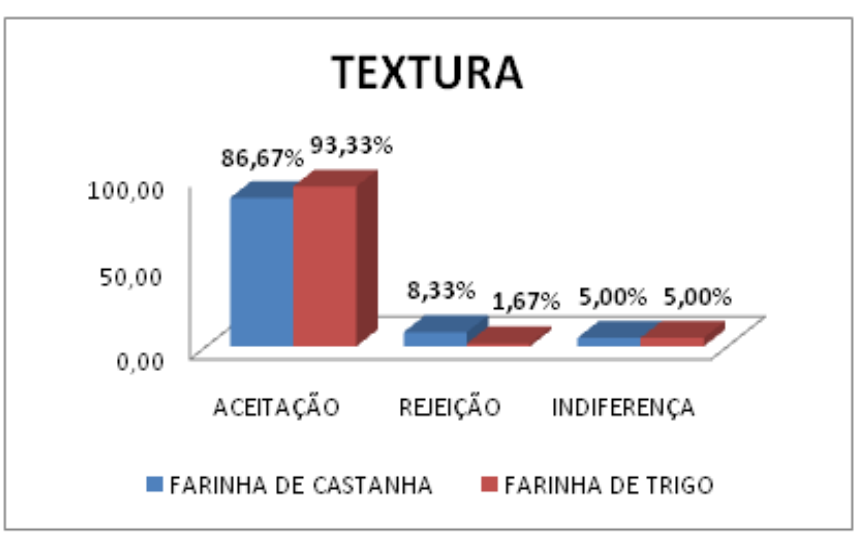

FIGURA 4. Histograma de frequência para textura 
De acordo com os dados, as amostras foram aceitas quanto à impressão global, aparência, sabor e textura. A amostra de PIZZA COM FARINHA DE AMÊNDOAS DA CASTANHA DE CAJU, sendo um novo produto, apresentou uma ótima aceitação quanto aos atributos analisados, pois obtiveram percentuais acima de $70 \%$ para a zona de aceitação dos respectivos atributos.

Intenção de compra

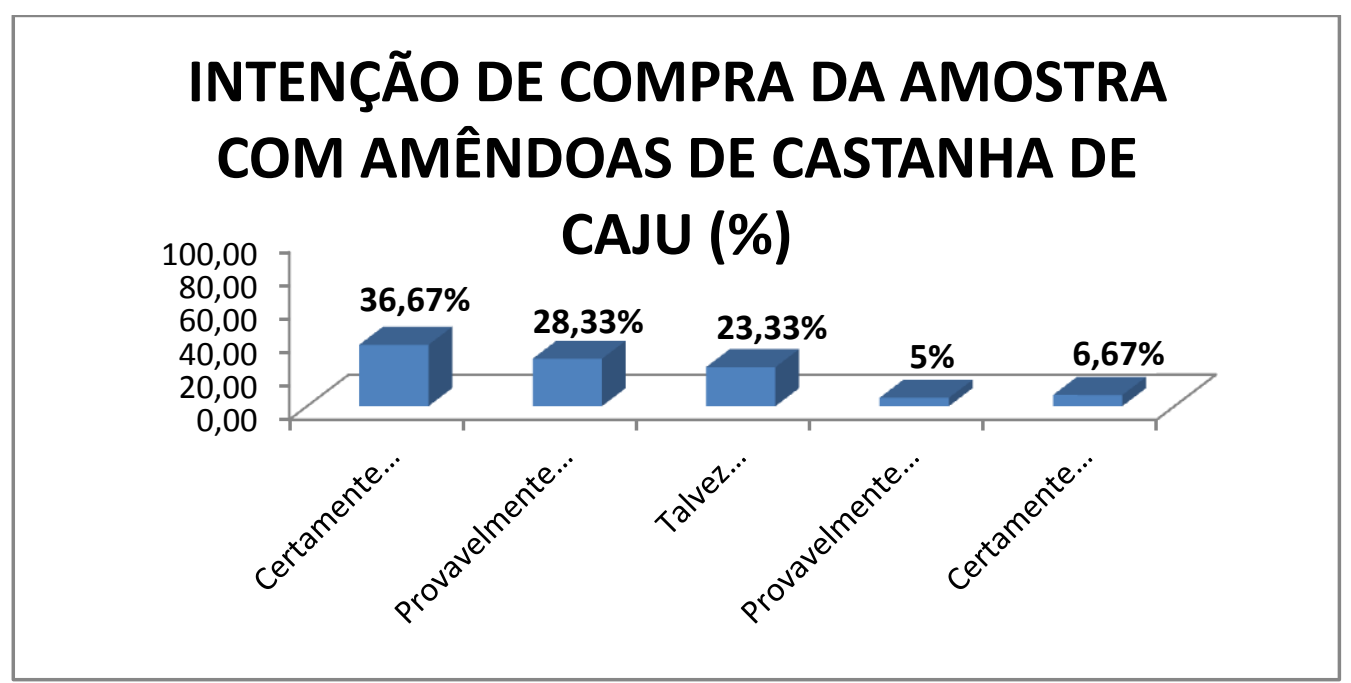

FIGURA 5. Intenção de compra da amostra com farinha de castanha

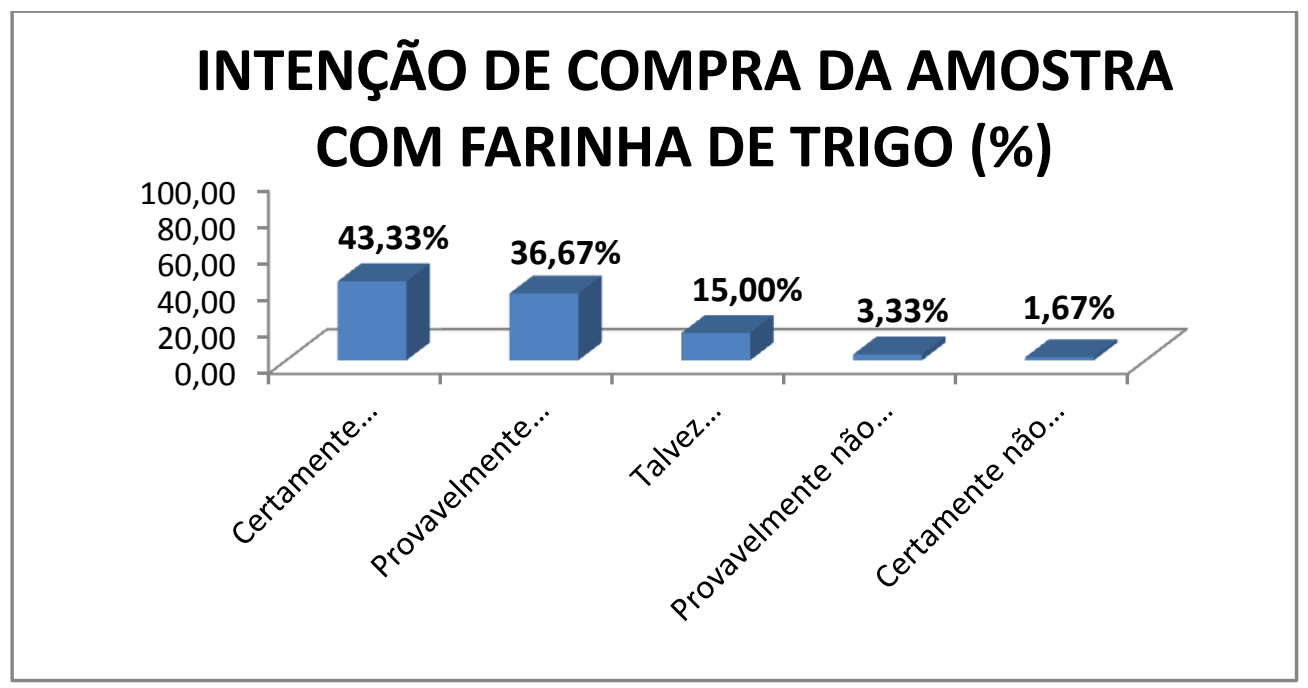

FIGURA 6. Intenção de compra da amostra com farinha de trigo 
De acordo com os resultados obtidos para intenção de compra, podemos notar que os maiores percentuais estão em PROVAVELMENTE COMPRARIA e CERTAMENTE COMPRARIA tanto para a nova formulação da pizza quanto para a pizza já existente no mercado. Portanto, os resultados mostram que se inserida no mercado a pizza com nova formulação (com farinha de amêndoas da castanha de caju) poderia apresentar uma boa aceitação, e, provavelmente, o consumidor iria adquiri-la.

\section{Conclusão}

Diante das análises dos resultados pode-se concluir que as formulações não diferiram significativamente em termos de aceitação dos provadores, e a utilização das amêndoas da castanha de caju na produção de massas de pizzas deve ser mais explorada, tendo em vista que esse produto mostrou-se bastante viável no que se diz respeito à aceitabilidade. Esta farinha mostra-se, também, uma interessante alternativa para os portadores da doença celíaca, por ser isenta de glúten, além de agregar um maior valor nutricional a pizza, se comparada com a pizza tradicional de farinha de trigo, devendo ser estudada a sua aplicação em outras formulações como de pães, bolos, biscoitos e etc. Portando, se introduzida no mercado, provavelmente, apresentaria uma porcentagem expressiva de compradores.

\section{Referências}

COSTA, Tereziana Silva da et al. Avaliação Sensorial de Massa de Pizza Enriquecida com Farinha do Resíduo de Extração do Amido da Amêndoa da Manga (Mangifera indica L.). Enect, Paraíba, v. 1, n. 1, p.1-10, 2012. Anais.

FARIAS, Adenilma da Silva. Massas para pizza com restrição de glúten. 2009. 42 f. Monografia (Especialização) - Curso de Especialização em Qualidade de Alimentos, Universidade de Brasília, Brasília, $2009 . \quad$ Disponível em: <http://webcache.googleusercontent.com/search?q=cache:http://bdm.bce.unb.br/handle/10483/1034 >. Acesso em: 08 dez. 2013.

FREITAS, Camila Andréa Favaro de et al. Avaliação Sensorial de Três Diferentes Tipos de Massa de Pizza. 2013. Ebaloradas por Docente e Acadêmicas da Faculdade de Três Lagoas. Disponível em: $\quad<$ http://www.aems.com.br/conexao/edicaoatual/Sumario-2/downloads/2013/1 $\quad$ (12).pdf>. Acesso em: 8 dez. 2013.

HATANDA, Telma Akemi et al. Elaboração de Massa de Pizza Enriquecida com Aveia. UNIVERSIDADE FEDERAL DE VIÇOSA CENTRO DE CIÊNCIAS BIOLÓGICAS E DA SAÚDE DEPARTAMENTO DE NUTRIÇÃO E SAÚDE. Disponível em: <http://www.leea.ufv.br/docs/6 ELABORAÇÃO DE MASSA DE PIZZA ENRIQUECIDA COM AVEIA.PDF>. Acesso em: 9 dez. 2013.

MARCOLINO, Brenda Natália Vieira et al. Análise Sensorial de Biscoito Tipo Cookie Elaborado com Substituição Parcial de Farinha de Trigo por Farinha de Castanha de Caju, Casca de Banana Verde e Uva. Enect, Paraíba, v. 1, n. 1, p.1-10, 2012. Anais. Disponível em: <http://editorarealize.com.br/revistas/enect/trabalhos/Poster_453.pdf>. Acesso em: 16 dez. 2013. 
SEMANA DE INTEGRAÇÃO ENSINO, PESQUISA E EXTENSÃO, 2009, Santa Cruz. Elaboração de Massa de Pizza sem Glúten com a Utilização de Farinha de Arroz. Santa Cruz, 2009. 4 p. Disponível em: <http://www.emdoc-consultorio.com.br/gluten-lactose/Massa de Pizza Sem Gluten Utilizando Farinha de Arroz.pdf>. Acesso em: 9 dez. 2013.

VILELA, Pierre. Castanha de caju. Disponível em: <http://www.sebrae.com.br/setor/fruticultura/osetor/frutas-de-a-a-f/castanha-de-caju>. Acesso em: 08 dez. 2013.

VINHAS, Ana D' EÇaMorgenstern . Elaboração e avaliação sensorial de massa de pizza com adição de fibra de soja. 2011. 87 f. TCC (Graduação) - Curso de Engenharia de Alimentos, Departamento de Instituto de Ciências e Tecnologia de Alimentos, 1 Universidade Federal do Rio Grande do Sul, Porto Alegre, 2011. Disponível em: <https://www.lume.ufrgs.br/bitstream/handle/10183/56087/000857671.pdf?sequence=1>. Acesso em: 8 dez. 2013. 